\title{
Learned flavor preferences based on calories are independent of initial hedonic value
}

\author{
RONALD MEHIEL and ROBERT C. BOLLES \\ University of Washington, Seattle, Washington
}

\begin{abstract}
In three experiments, the learning of flavor preferences due to pairing with calories was examined. In Experiment 1, the relative hedonic values of four isocaloric solutions and saccharin were assessed by offering these substances simultaneously to naive rats. The caloric solutions were then used to condition a flavor preference in separate groups of rats. Although the solutions were reliably different in unconditioned hedonic value, the conditioned flavor preferences were identical. In Experiment 2, we compared solutions of sucrose and saccharin that were equal in unconditioned hedonic value. Only the sucrose conditioned a preference. Finally, in Experiment 3, preferences were found to be sensitive to the number of calories available during conditioning. These results are discussed in terms of a peripheral cholecystokinin (CCK) reflex and the integration of that information along with taste information at the area postrema (AP) and surrounding nuclei. It is proposed that CCK acts centrally to adjust the incentive motivation or hedonic value of flavors.
\end{abstract}

When a novel flavor is paired with a caloric solution such as sucrose, Polycose, or ethanol, rats learn to prefer that novel flavor (Fedorchak \& Bolles, 1987, in press; Mehiel \& Bolles, 1984, 1986, 1987; Messier \& White, 1984; Sclafani \& Elizalde, in press; Simbayi, Boakes, \& Burton, 1985, 1987). It is tempting to conclude that what makes this kind of hedonic shift possible is the positive postingestional consequences of drinking the caloric solution. But there is a problem: usually the caloric solution has a high unconditioned hedonic value. That is, the rat likes it the first time it tastes it. Saccharin, which has a sweet taste but no caloric effect, can also condition a preference for a paired flavor (Fanselow \& Birk, 1982; Messier \& White, 1984). Sugars and starches, both highly preferred by rats, are often used as calorie sources in these conditioned taste-preference studies. However, there is evidence that rats learn to like the taste of flavors paired with ethanol (Bolles \& Mehiel, 1982; Crawford \& Baker, 1982; Mehiel \& Bolles, 1984; Sherman, Hickis, Rice, Rusiniak, \& Garcia, 1983). In the case of ethanol, which generally is regarded as having a negative taste, only those concentrations below $10 \%$ will serve to condition a preference for a paired flavor (Mehiel \& Bolles, 1984). Perhaps what appears to be calorie conditioning is really a case of taste conditioning. When the rat learns to like a flavor paired with some tasty caloric solution, the hedonic shift for the paired flavor might be due to a flavor-flavor mechanism and not to postingestional consequences.

In order to separate the unconditioned hedonic aspects of caloric solutions from their postingestional effects, we held the one constant and varied the other. In Experiment 1 , we held the caloric density of flavor-preference conditioning solutions constant while the unconditioned hedonic value varied. In Experiment 2, the hedonic value

R. Mehiel's present address is Department of Psychology, Shippensburg University, Shippensburg, PA 17257. was constant while the caloric value varied. Finally, in Experiment 3, we held the caloric density constant but varied the absolute number of calories available during the conditioning trials.

\section{EXPERIMENT 1}

We reasoned that if the learned preference for a flavor paired with caloric solutions was due to the unconditioned hedonic value of the calorie source, and not to the caloric value per se, then preferences would be positively correlated with unconditioned hedonic value when equal caloric values were compared. We used four distinct isocaloric sources: sucrose, starch, ethanol, and corn oil. We first offered a group of rats all the solutions simultaneously, to assess the hedonic values in a within-rat test. We then paired a novel flavor with the solutions, in independent groups, in a conditioning paradigm known to foster the development of a learned preference for the novel flavor (Mehiel \& Bolles, 1984). All the groups learned a preference for the paired flavor, and there were no differences among the groups in the strength of the preference, even though the solutions differed in unconditioned hedonic value.

\section{Method}

Subjects. Fifty-four male Long-Evans rats served as subjects. The rats were 90 days old at the start of the experiment. They were housed individually in hanging metal cages, at $21^{\circ} \mathrm{C}$ in a room with lights on at $0800 \mathrm{~h}$ and off at $2000 \mathrm{~h}$ daily. The rats were fed $12 \mathrm{~g}$ of Purina Rat Chow at $0830 \mathrm{~h}$ daily, except as noted below. Water was freely available, except during testing and conditioning.

Solutions and flavors. The solutions were calibrated to deliver $.289 \mathrm{kcal} / \mathrm{ml}$. Sucrose (table sugar) and Polycose (hydrolized corn starch, Ross Labs) were $7.6 \% \mathrm{w} / \mathrm{v}$, ethanol was $5 \% \mathrm{v} / \mathrm{v}$, and corn oil (Wesson; Beatrice, Inc.) was 3\% v/v with granulated lecithin $(1 \% \mathrm{w} / \mathrm{v})$ added as an emulsifier. Sodium saccharin $(.25 \% \mathrm{w} / \mathrm{v})$ served as the noncaloric solution. The flavors added to the solutions during the conditioning phase were either orange or lime (un- 


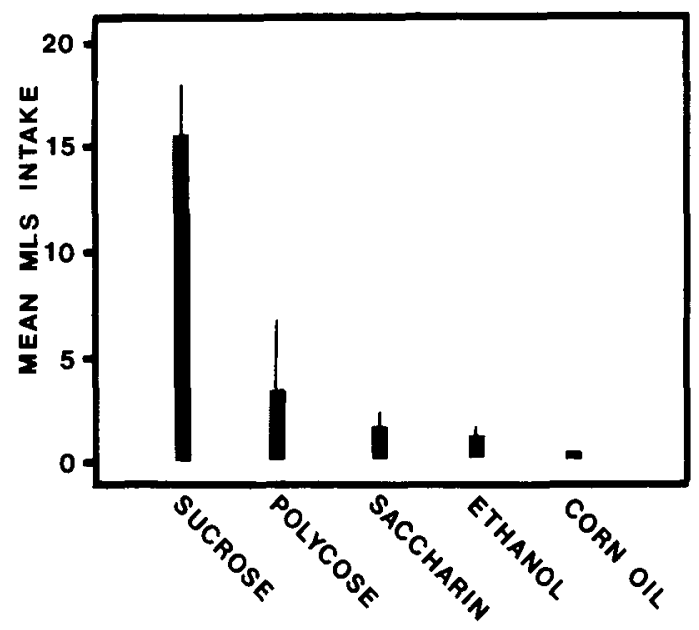

Figure 1. Mean intakes of the five unconditioned solutions in Experiment 1.

sweetened Kool Aid, General Foods), one 5 g package in $1600 \mathrm{ml}$ water. The flavored solutions were mixed by first making the orangeor lime-flavored water, then adding the appropriate amount of saccharin, sucrose, Polycose, ethanol, or oil and lecithin. All the solutions were mixed in a blender at high speed for $20 \mathrm{sec}$. Fresh solutions were made daily, $1 \mathrm{~h}$ before presentation to the rats; the solutions were allowed to stand at room temperature during that hour. The solutions were delivered to the rats via $250-\mathrm{ml}$ glass or 45-ml plastic bottles with rubber stoppers and metal tubes.

Procedure for assessment of unconditioned hedonic values. Twenty-two free-feeding rats served in this phase of the experiment. At $0800 \mathrm{~h}$ on the day of the test, all Rat Chow was removed from the cages, and the five-bottle test with unflavored saccharin, sucrose, Polycose, ethanol, and oil with lecithin ensued. Intakes were measured after $3 \mathrm{~h}$. Since the rats were accustomed to eating mainly at night, the test took place when feeding was minimal. In fact, the rats usually slept during that time. We wanted to assess the hedonic value of the four caloric solutions at a time when intake was primarily based on taste, not hunger. The intakes were subjected to a repeated measures analysis of variance.
Conditioning of preference. The remaining 32 rats were assigned to four groups of 8 animals that differed according to source of calories (SUG, POLY, ETH, OIL), and a preference was conditioned for either orange or lime flavor by pairing one flavor with one of the caloric solutions and the other flavor with saccharin. On Day 1 of conditioning all the rats had their water bottles replaced by flavored saccharin (except as noted below) $30 \mathrm{~min}$ after their daily $12 \mathrm{~g}$ ration of Rat Chow. For half of each group the saccharin was orange flavored, while for the other half it was lime flavored. On Day 2, at $0800 \mathrm{~h}$, the bottles were removed, the rats were fed again, and the intakes were measured. Each rat was then allotted an amount of calorie solution equal to its intake of flavored saccharin. The calorie solution was flavored with either orange or lime, so that each rat had one flavor with saccharin and one flavor with calories. All odd days were like the first, while all even days were like the second. Since pilot work had shown that the rats would drink more saccharin than either ethanol or oil, the yoking procedure was reversed for the latter two groups. Conditioning proceeded in this manner for $\mathbf{1 0}$ days. Water and ad-lib Purina were then returned for 5 days; then all food was removed for $24 \mathrm{~h}$, and at $0800 \mathrm{~h}$ on Day 17, a two-bottle test with orange- and lime-flavored water ensued. No food was available to the rats during the test, which lasted $3 \mathrm{~h}$ and concluded the experiment. The rat's intake of calorie-paired flavor was subjected to a between-subjects ANOVA, with calorie source as the treatment factor.

\section{Results and Discussion}

The results of the unconditioned hedonic value test are presented in Figure 1. The ANOVA revealed reliable differences between the means $[F(4,7)=11.96, p<$ $.01]$. Intake during conditioning and during the flavor test is presented in Figure 2. Intake of the calorie-paired flavor did not differ across groups, nor did intake of the waterpaired flavor $[F(3,28)=1]$. The preference for the calorie-paired flavor was reliable in each group $[F(1,6)$ $=281.8]$

The notion that learned preference for a flavor paired with a caloric solution is due to a transfer of unconditioned hedonic value from the solution (say, sugar) to the flavor paired with it cannot be supported. While there is solid

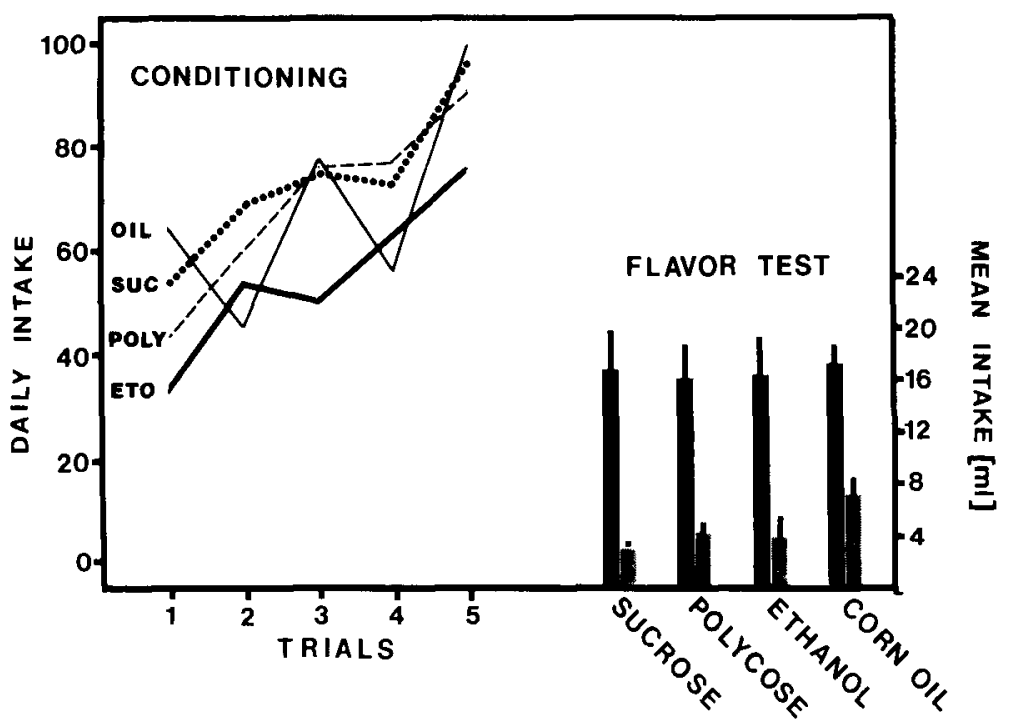

Figure 2. Mean daily intake of solutions during conditioning, and intake of paired flavors during the test. The dark bars represent favor paired with calorie solution; the light bars represent flavor paired with saccharin. 
evidence for that kind of flavor-flavor learning mechanism (Fanselow \& Birk, 1982), it appears to have contributed very little to the outcome of the present experiment. Perhaps a flavor-flavor mechanism occurs early in the experience of tasting a flavored solution, and if the experimental protocol allows it, this is followed by a postingestional mechanism sensitive to calories, which serves to further shift the hedonic value of the paired flavor. Despite the reliable differences in unconditioned hedonic value of the experimental solutions, intakes of the paired flavors following conditioning were almost identical. The best predictor of the degree of preference was the caloric value of the conditioning solution. However, it was possible that our results were simply due to differences in sensitivity between the initial within-rat test of hedonic value and the following between-rats test of differences in conditioning. If we could show that holding unconditioned hedonic value constant while letting calories vary led to differences in conditioning, then our argument would be strengthened.

\section{EXPERIMENT 2}

Messier and White (1984) offered rats various solutions of sucrose and saccharin in an attempt to find two equally acceptable levels of sweetness. They reported that $20 \% \mathrm{w} / \mathrm{v}$ sucrose and $.8 \% \mathrm{w} / \mathrm{v}$ saccharin were consumed equally, and so they concluded that the solutions were equal in hedonic value. Using that information, we offered independent groups of rats one flavor with either sucrose or saccharin, and another flavor with water; then we tested for preference.

\section{Method}

Subjects. Eight male Long-Evans rats 90 days old served in Experiment 2. The rats were maintained exactly as in Experiment 1.

Solutions. Sucrose $(20 \% \mathrm{w} / \mathrm{v})$ and saccharin $(.8 \% \mathrm{w} / \mathrm{v})$ were prepared as in Experiment 1. Added flavors were again Kool Aid, either cherry or grape.

Procedure. The 8 rats were randomly assigned to two groups of 4. One group (SUG) had sucrose paired with one flavor and tap water paired with the other flavor. The other group (SACCH) had saccharin paired with one flavor and water paired with the other. Flavors were balanced within groups. On the first day of conditioning, all the rats were presented with flavored water. On the next day, the water was removed, consumption was measured, and each rat was presented with an amount equal to the first day's consumption, of either flavored sucrose or saccharin (depending on group). Conditioning proceeded for 8 more days, with odd days replicating the first and even days replicating the second. Following conditioning, both groups received a two-bottle test with cherry- and grape-flavored water that lasted $1 \mathrm{~h}$.

\section{Results and Discussion}

Intakes during both conditioning and the test are presented in Figure 3. A split plot ANOVA (Edwards, 1985 , p. 342) on test intake revealed that the main effect for flavor paired with sweetness was reliable $[F(1,6)=$ $6.3, p<.05]$, and that the interaction between group and sweet flavor was significant $[F(1,6)=14.8, p<.01]$. The interaction reveals that the preference for the sweet-

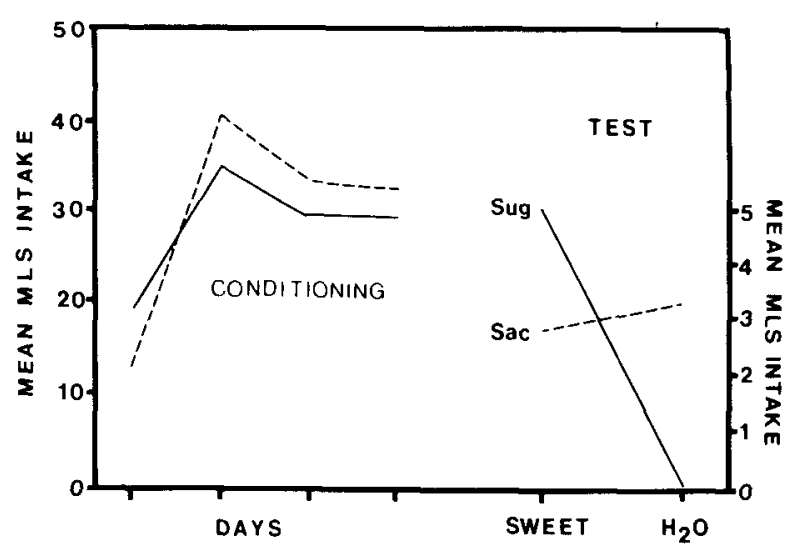

Figure 3. Mean intake of flavored solutions during conditioning, and the paired flavor during the test, in Experiment 2. The dashed line represents the saccharin group; the solid line represents the sugar group.

paired flavor was only reliable in the SUG group. In fact, not one rat in Group SUG drank any of the water-paired flavor in the test. Group SACCH failed to develop a preference for either flavor $[F(1,5)=5.0, p<1.0]$. These results appear to be surprising, since rats typically prefer flavors paired with saccharin. However, we used a saccharin concentration much stronger than that most preferred by rats ( .8 vs. .25 ), in order to equate unconditioned hedonic value. Additionally, our procedure gave the rats more experience with saccharin than the typical flavor-flavor experiment allows (cf. Fanselow \& Birk, 1982; Holman, 1975).

However, the main interesting result is that when unconditioned hedonic value was held constant and caloric value varied, caloric value was still the best predictor of learned preference. In addition to these data, it should be noted that in Experiment 1 the unconditioned hedonic value of saccharin was higher than that of either oil or ethanol; yet the rats learned to prefer the calorie-paired flavor over the saccharin-paired flavor.

In Experiment 1, hedonic value was varied while caloric density was held constant. Conditioned preferences did not vary, so we concluded that unconditioned hedonic value contributed very little to the learned preferences. In Experiment 2, hedonic value was held constant while caloric density was either 1.15 or $0 \mathrm{kcal} / \mathrm{ml}$. Only the rats that got caloric solutions learned a preference for the paired flavor. Another way to manipulate calories is to vary the absolute number of calories available to the rat, while holding caloric density constant. In Experiment 3, we looked at this issue.

\section{EXPERIMENT 3}

In Experiment 2, we manipulated caloric value by comparing the conditioning efficacies of a sweet caloric solution and a sweet noncaloric solution. In Experiment 3, we held caloric density constant (as in Experiment 1) but varied the quantity of solution available during the conditioning trials. In order to examine the effect of varying 
the amount of available calories, we simply offered the rats more of the caloric solution than of the noncaloric solution in some groups, and reversed the relationship in others.

\section{Method}

Subjects. Thirty-six male, 90-day-old Long-Evans rats served as subjects. The rats were housed and maintained as in Experiments 1 and 2.

Solutions. Polycose $(7.6 \% \mathrm{w} / \mathrm{v})$ and saccharin $(.25 \% \mathrm{w} / \mathrm{v})$ were used as the conditioning solutions. The flavors were either orange or lime Kool Aid, counterbalanced within groups. Solutions and flavors were prepared as in Experiment 1.

Procedure. The rats were assigned to six groups of 6 each. The groups differed according to how much of each conditioning solution they received. The possible amounts were 20,40 , and $60 \mathrm{ml}$ per day for each of the solutions. Table 1 shows the $3 \times 3$ comparisons that formed the groups. Note that the cells along the diagonal are essentially a replication of Experiment 1 , in which the amounts were yoked. Those three groups were not run. The present six groups fill in the off-diagonal cells of the table. Within each group we balanced paired flavor and order of presentation. In other words, half the rats started conditioning with Polycose and half with saccharin; half had lime saccharin and orange Polycose, half had the flavors reversed. Conditioning proceeded as in the previous experiments for 10 days, alternating daily between Polycose and saccharin. Following the conditioning phase, the rats had ad-lib food and water for 4 days, then were deprived of chow for $24 \mathrm{~h}$, and finally were offered a two-bottle test with lime- and orange-flavored water, which lasted $3 \mathrm{~h}$.

\section{Results and Discussion}

During conditioning, every rat drank all of the conditioning solutions. The results of the two-bottle test are presented in Table 2. Analysis revealed that all groups preferred the Polycose-paired flavor $[F(1,30)=14.38$, $p<.001]$. Planned comparisons between the two groups at each level of amount of available Polycose $(20,40$, and $60 \mathrm{ml}$ ) revealed no differences within levels, but differences among the groups at all three levels approached significance $(20-40, p=.07 ; 20-60, p=.06,40-60, p=$ .12). A test of the linearity of the collapsed means revealed a significant linear component to the means $[F(1,33)=4.19, p<.05]$.

In Experiment 1, all the groups had equally caloric solutions during conditioning, and we concluded that caloric value was a better predictor of learned flavor preference than unconditioned hedonic value was. In Experiment 3 , both the hedonic value and the caloric density of the caloric solution were equal across groups, but the absolute number of calories paired with the flavor was varied. Both the presence of calories and unconditioned

Table 1

Amount (ml per day) of Polycose and Saccharin Available During Conditioning for the Six Groups in Experiment 3

\begin{tabular}{ccccc}
\hline & & \multicolumn{3}{c}{ Polycose } \\
& & 20 & 40 & 60 \\
Saccharin & 20 & & $X$ & X \\
& 40 & $X$ & & X \\
\hline
\end{tabular}

Note-The six calls off the diagonal formed the groups in Experiment 3.
Table 2

Preference Ratio for Polycose-Paired Flavor from the Test in Experiment 3

\begin{tabular}{ccccc}
\multicolumn{6}{c}{ from the Test in Experiment 3 } \\
\hline \multicolumn{5}{c}{ Polycose } \\
Saccharin & 20 & & 40 & 60 \\
& 40 & .61 & .57 & .76 \\
& 60 & .61 & .65 & .73 \\
\hline
\end{tabular}

Note-Numerals refer to amount of Polycose or saccharin, in milliliters per day.

hedonic value predicted the learned preference. However, the learned preference was sensitive to the absolute number of calories available during the conditioning trial.

\section{GENERAL DISCUSSION}

The present set of experiments demonstrates that unconditioned hedonic value contributes little to what we call calorie conditioning. Postingestional effects of calories seemed to initiate the preference learning in this conditioning paradigm.

If it is true that equally caloric solutions condition equal preferences for paired flavors, then we are led to postulate that animals have some kind of calorie counter, and as it happens, they do. McHugh and Moran (1986) and others have demonstrated convincingly that one result of loading the stomach with caloric substances is a graded reflexive response involving cholecystokinin (CCK). This reflex presumably serves to let the animal maximize its ability to absorb energy from the caloric substance, since caloric solutions empty from the stomach to the duodenum at a remarkably constant rate, whereas noncaloric solutions are dumped rapidly (McHugh \& Moran, 1986). Additionally, there is clear evidence that this peripheral CCK reflex is monitored via receptors on afferent vagal fibres (Sankaran, Deveney, Goldfine, \& Williams, 1979; Zarbin, Wamsley, Innis, \& Kuhar, 1981) that terminate in or near the area postrema (AP) at the caudal portion of the nucleus of the solitary tract (NTS). The AP, a circumventricular organ, is thus able to sample from the cerebrospinal fluid in the fourth ventrical; it would therefore be sensitive to circulating CCK. Moran, Robinson, Goldrich, and McHugh (1986) have characterized two types of CCK receptors in the rat brain. One is widespread and relatively nonspecific. The other, located in or near the AP, has receptors that are specific for circulating hormonal CCK. The NTS also receives sensory information about taste from other vagal fibres, as does the gustatory nucleus, which is just superior to the NTS via the glossopharangeal nerve. Additionally, the AP and caudal portion of the NTS contain neurons whose axons project rostrally to the amygdala and lateral parabrachial nucleus, and from there to the lateral and paraventricular hypothalamic nuclei. Some of these connections are reciprocal. That is, the higher structures also send axons caudally to the AP and the NTS (Barone, Wayner, Scharoun, Guerra-Aguilar, \& Aguilar-Baturoni, 1981; Hosoya and Mashushita, 1981; Kott, 1987; Norgren, 1978; Ricardo 
\& Koh, 1978; Shapiro \& Miselis, 1985; van der Kooy, 1984; van der Kooy \& Koda, 1983).

It is tempting to speculate that these kinds of circuits have evolved to integrate information about the taste and postingestional effects of solutions or food, in order to modulate the hedonic properties of the taste.

There is a bit of evidence that the peripheral CCK reflex operates on the central nervous system to adjust motivational levels in the animal. If one views the two-bottle flavor preference test used by us and others as a measure of the incentive motivational quality of the flavors, then some recent findings may be seen to support the ideas discussed above. Fedorchak and Bolles (1988) had rats drink a flavor that was either paired or unpaired with ethanol. Following a number of days of this conditioning, the rats were injected with either CCK or saline. CCK reduced the intake of the target flavor only when it had been paired with ethanol. To explain this result, Fedorchak invoked a nutritive expectancy on the part of the rats. In other words, the peripheral effects of CCK were secondary. The drug only affected the preference when the flavor had come to represent a calorie source for the animal due to its conditioning history. There is also the finding that, in sheep, the suppression-of-intake effects of CCK are modulated by the hunger level of the animal at the time of the test (Baile \& Della-Fera, 1985). Further evidence for the motivational effects of CCK were recently offered by Zhang, Bula, and Stellar (1986). They trained mildly deprived rats to run from one end of a runway to the other for a wet mash reward. Both intraperitoneal and intraventricular injections of CCK led to a clear and dramatic decrease of running speed when the rats were $18 \mathrm{~h}$ fooddeprived. When the rats, having been made thirsty, then ran to water, the drug had no effect.

It seems clear that the effects of CCK interact with motivation. Perhaps ingested flavors that lead to a reflexive CCK response, because they have been linked with calories, take on incentive motivational qualities. Isocaloric solutions could result in equally strong CCK responses at the gut, and the result would be equal incentive value for the flavors in the test. This may be how the rat learns to like what it needs.

\section{REFERENCES}

Baile, C. A., \& Della-Fera, M. A. (1985). Central nervous system cholecystokinin and the control of feeding. In J. Vanderhaeghen and J. N. Crawley (Eds.), Annals of the New York Academy of Sciences: Vol. 448. Neuronal cholecystokinin (pp. 424-435). New York: Academy of Sciences.

Barone, F. C., Wayner, M. J., Scharoun, S. L., Guerra-Agullar, R., \& AgUilar-Baturoni, H. U. (1981). Afferent connections to the lateral hypothalamus: A horseradish peroxidase study in the rat. Brain Research Bulletin, 7, 75-88.

Bolles, R. C., \& MEHIEL, R. (1982). Conditioned taste preferences based on the calories in ethanol. Paper presented at the 23rd annual meeting of the Psychonomic Society, Minneapolis, MN.

Crawford, D., \& BAKER, T.B. (1982). Alcohol dependence and tastemediated learning in the rat. Pharmacology, Biochemistry \& Behavior, 16, 253-261.

EDWARDS, A. L. (1985). Experimental design in psychological research. New York: Harper \& Row.
FANSElow, M., BiRK, J. (1982). Flavor-flavor associations induce hedonic shifts in taste preference. Animal Leaming \& Behavior, 10. 223-228

Fedorchak, P. M., \& Bolles, R. C. (1987). Hunger enhances the expression of calorie- but not taste-mediated conditioned flavor preferences. Journal of Experimental Psychology: Animal Behavior Processes, 13, 73-79.

Fedorchak, P. M., Bolles, R. C. (1988). Nutritive expectancies mediate cholecystokinin's suppression-of-intake effect. Behavioral Neuroscience, 102, 451-455

HoLman, E. (1975). Immediate and delayed reinforcers for flavor preference in rats. Learning \& Motivation, 6, 91-100.

Hosoya, Y., \&Ashushita, M. (1981). Brainstem projections from the hypothalamus to the area postrema in the rat, as by the HRP and autoradiographic methods. Brain Research, 214, 144-149.

Kотт, J. N. (1987). Dorsal medullary factors in pancreatic regulation. Unpublished doctoral dissertation, University of Washington, Seattle.

McHugh, P. R., \& Moran, T. H. (1986). The stomach, cholecystokinin, and satiety. Federation Proceedings, 45, 1384-1390.

MEHIEL, R., \& BolLES, R. C. (1984). Leamed flavor preferences based on caloric outcome. Animal Learning \& Behavior, 12, 421-427.

MEHIEl, R., BolLES, R. C. (1986). Flavor preference learning: Effects of calories and exposure. Paper presented at the S6th annual meeting of the Eastern Psychological Association, New York

MEHIEl, R., Bolles, R. C. (1987). A comparison of calorie-based conditioned taste preferences from various sources. Paper presented at the 57th annual meeting of the Eastern Psychological Association, Arlington, VA.

Messier, C., White, N. M. (1984). Contingent and non-contingent actions of sucrose and saccharin reinforcers: Effects on taste preference and memory. Physiology \& Behavior, 32, 195-203.

Moran, T., Robinson, P.H., Goldrich, M.S., McHugh, P.R. (1986). Two brain cholecystokinin receptors: Implications for behavioral actions. Brain Research, 362, 175-179.

Norgren, R. (1978). Projections from the nucleus of the solitary tract in the rat. Neuroscience, 3, 207-218.

Ricardo, J. A., \& KoH, E. T. (1978). Anatomical evidence of direct projections from the nucleus of the solitary tract to the hypothalamus, amygdala, and other forebrain structures of the rat. Brain Research, $153,1-26$

Sankaran, H., Deveney, C. W., Goldfine, I. D., \& Wiluams, J. A. (1979). Preparation of biologically active radioiodinated cholecystokinin for radioreceptor assay and radioimmunoassay. Jourmal of Biological Chemistry, 254, 9349-9351.

SClafani, A., Elizalde, G. (in press). Starch-based conditioned flavor preferences in rats: Influence of taste, calories, and CS-US delay. Appetite.

Shapiro, R. E., Miselis, R. R. (1985). The central connections of the area postrema of the rat. Journal of Comparative Neurology, 234, 344-346.

Sherman, J. E., Hickis, C. F., Rice, A. G., Rusiniak, K. W., GarCIA, J. (1983). Preferences and aversions for stimuli paired with ethanol in hungry rats. Animal Learning \& Behavior, 11, 101-106.

Simbayi, L. C., Bonkes, R. A., \& Burton, M. J. (1985). Acquired preferences for flavours mixed with nutritive and non-nutritive sweet solutions. Neuroscience Letters, 22(Suppl.), S158.

Simbayi, L. C., Boakes, R. A., Burton, M. J. (1987). Can rats learn to associate a flavour with the delayed delivery of food? Appetite, 7, 41-53.

VAN DER KOOY, D. (1984). Area postrema: Site where cholecystokinin acts to decrease food intake. Brain Research, 295, 345-347.

VAN DER KOOY, D., \& KODA, L. Y. (1983). Organization of the projections of a circumventricular organ: The area postrema in the rat. Journal of Comparative Neurology, 219, 328-338.

Zarbin, M. A., Wamsley, J. K., InNis, R. B., Kuhar, M. J. (1981). Cholecystokinin receptors: Presence and axonal flow in the rat vagus nerve. Life Sciences, 29, 697-705.

Zhang, D., Bula, W., Stellar, E. (1986). Brain cholecystokinin as a satiety peptide. Physiology \& Behavior, 36, 1183-1186.

(Manuscript received October 15, 1987; revision accepted for publication May 10, 1988.) 